\title{
The effect of the pre-wetting of expanded clay aggregate on the freeze-thaw resistance of the expanded clay aggregate concrete
}

https://doi.org/10.2478/sgem-2020-0011

received October 21, 2020; accepted November 19, 2020.

\begin{abstract}
This paper presents experimental research on expanded clay aggregate concrete. The aim of the investigations was to determine if the pre-wetting of expanded clay aggregate has an effect on the freeze-thaw durability of the expanded clay aggregate concrete. Five concrete series based on the same concrete mix design were made and tested. The degree of pre-wetting of the aggregate was varied: dry aggregate was used in the first series, aggregate with a moisture content of $10 \%$ was used in series IA and IB and aggregate with a moisture content of $25 \%$ was used in series IIA and IIB. Also the approach to the production process was varied: in series A the water contained in the aggregate was taken into account in the global water-cement ratio (consequently a reduced amount of water was added to the mix), whereas in series B the nominal amount of water was added to the mix (as in the case of dry aggregate). The freeze-thaw resistance criterion was based on the assessment of the decrease of compressive strength and increase in weight loss after exposure to freeze-thaw cycles. The expanded clay aggregate concrete's strength and mass decrements caused by freeze-thaw cycling were used as the measure of its freeze-thaw resistance. The investigations have shown that the pre-wetting of expanded clay aggregate has an effect on the freeze-thaw durability of the expanded clay aggregate concrete. The differences of concrete compressive strength decrease related to freezethaw durability may be 2 to 5 times greater when inadequate method of calculating mixing water for concrete is used.
\end{abstract}

Keywords: lightweight concrete; freeze-thaw resistance; aggregate pre-wetting.

\footnotetext{
*Corresponding author: Michat Piotr Musiat, Wroclaw University of Science and Technology: Politechnika Wroclawska, Wroctaw, Poland, E-mail: michal.musial@pwr.edu.pl

Filip Grzymski, Tomasz Trapko, Wroclaw University of Science and Technology, Politechnika Wroclawska, Wroctaw, Poland
}

\section{Introduction}

Lightweight aggregate concrete, abbreviated LWAC or LAC, is a special concrete in which porous aggregate of low density is used (Kucharczyková et al, 2012). Typically, lightweight concrete is characterized by a bulk density of $300-1,850 \mathrm{~kg} / \mathrm{m}^{3}$, but in practice, it has become customary to use concrete with a bulk density of $1,350-1,900 \mathrm{~kg} / \mathrm{m}^{3}$ as structural concrete. Concrete with a lower density is most often classified as medium strength concrete. Concrete with a density below $800 \mathrm{~kg} / \mathrm{m}^{3}$ is classified as insulating concrete (Neville, 2011). Thanks to the considerably lower specific weight of LAC the permanent loads in a designed concrete structure will be lower, whereby the overall dimensions of the supports and foundations bearing the weight of the structure made of LAC (instead of conventional concrete) can be reduced. The reduction in specific weight relative to that of conventional concrete usually amounts to $16-36 \%$, but in extreme cases, it can reach $42 \%$, and when fine lightweight aggregate is used, it can be as large as 56\% (Rashad, 2018). In addition, owing to their lower density and the presence of air trapped in their pores, LAC is characterized by much better thermal performance than conventional concrete. This in the case of space-enclosing elements can lead to improved energy performance of the building (Rashad, 2017; Youm, Moon, Cho, \& Kim, 2016; Topçu \& Işıkdağ, 2008). Research shows that the use of lightweight aggregate can reduce the heat transmission coefficient from $0.8 \mathrm{~W} / \mathrm{m} \cdot \mathrm{K}$ (typical of conventional concrete) to below $0.3 \mathrm{~W} / \mathrm{m} \cdot \mathrm{K}$ (Rashad, 2018), and the use of LAC instead of conventional concrete can reduce the building's heat energy demand by over $30 \%$ (Youm et al, 2016). The good strength parameters combined with the relatively light specific weight of LAC make it an attractive material for practical use, for example, in building bridges (Youm et al, 2016). Besides their use in typical construction, LAC is also used in less typical structures, such as structural components of oil rigs (Haug \& Fjeld, 1996). Moreover, research indicates that the replacement of a part of ordinary aggregate with 


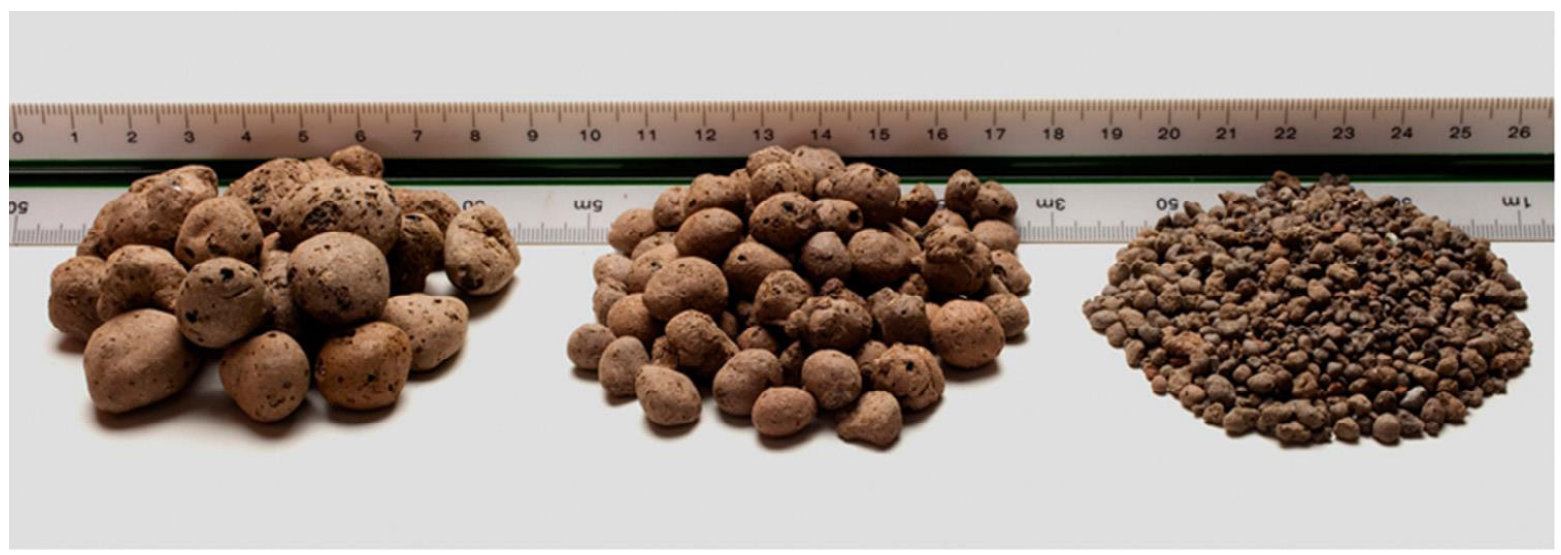

Figure 1: Lightweight aggregates differing in their diameter (from left to right: 8-16 mm, 4-8 mm, 2-4 mm) (Rashad, 2018).

lightweight aggregate can enhance the structural strength in earthquake conditions, owing to the lighter specific weight of LAC in comparison with conventional concrete (Topçu \& Işıkdağ, 2008).

Typical lightweight aggregate is produced by firing clay at the temperature of $1,100-1,300^{\circ} \mathrm{C}$. As the material's organic matter is being burnt, gases are released internally, whereby a porous structure forms. When the material cools down, its structure remains unchanged. In this way, porous aggregate is obtained. Such aggregate can be used in the production of concrete (Rashad, 2018). As a result of the process described above, the volume of the material can increase five-six-fold (Ozguven \& Gunduz, 2012). Originally, lightweight aggregates were made from natural minerals, but as the demand increased, this led to the depletion of natural sources. Besides clay, shales, schists, vermiculite, and pearlite are usually used in the aggregate production process (Neville, 2011). Because of the contemporary trend towards sustainable development and recycling, waste materials have begun to be used in the production of aggregates. This trend has become part of the European Green Deal, which consists in the more efficient use of resources owing to the transition to clean (closed-cycle) economy. Currently also, such commonly available coal combustion wastes as fly ash (Jo, Park, \& Park, 2007) and blast-furnace slag (Neville, 2011) are used in the production of artificial lightweight aggregates. Lightweightaggregates areproduced in varioussizes(fig.1), whereby they can be used as large aggregate or small (fine) aggregate. The typical bulk densities of lightweight aggregates are in the range of $250-710 \mathrm{~kg} / \mathrm{m}^{3}$, and they mainly depend on the aggregate grain size (Rashad, 2018).

Because of its aggregate, lightweight concrete differs from conventional concrete both as a concrete mix and hardened concrete. In the case of LAC, there is usually a higher risk of aggregate separation, but it is worthy of note that despite the higher water absorption by lightweight aggregate, no substantial decrease in concrete workability is observed, and in some cases, the workability of the concrete improves in comparison with conventional concrete. This is owing to the rounded shape and surface of lightweight aggregate, having a beneficial effect on concrete workability (Rashad, 2018). The mechanical properties of hardened concrete are closely dependent on the concrete mix design, and so, a direct comparison of the properties of conventional concrete and lightweight concrete is practically impossible. Nevertheless, an analysis of the relevant research shows a relatively consistent trend for concrete compressive strength to decrease by about 35\% when lightweight aggregate is used. This decrease in strength is extended further to $55 \%$ when lightweight aggregate is used as both large and small aggregate (Rashad, 2018).

One of the most important characteristics of LAC is its freeze-thaw durability. Research shows that the degree to which the aggregate is pre-saturated with water has a significant effect on the mechanical parameters and behaviour of the LAC. When completely dry aggregate is used, it takes mixing water away from the cement paste, locally lowering the water-cement ratio and so preventing the effective hydration of the cement around the aggregate. On the other hand, if completely watersaturated aggregate is used, this may result in a reduction in the strength of the matrix/aggregate contact zone due to the fact that the cement paste cannot penetrate into the pores of the aggregate. Therefore, it is recommended to strictly control the way in which aggregate is wetted (Kucharczyková et al, 2012; Kucharczyková, Keršner, Pospíchal, Misák, \& Vymazal, 2010). Investigations of the dynamic elastic modulus of LAC subjected to freezethaw cycling in accordance with ASTM C330 show significant differences in the behaviour of this material 
depending on the type of the aggregate used. One of the tested types of aggregate did not exhibit behaviour significantly different from that of conventional concrete made according to a similar concrete mix design. In the case of the other tested type of lightweight aggregate, a significant decrease in freeze-thaw durability was noted. According to the authors, the cause of this decrease was the high water demand of the other tested aggregate. The above investigations also showed that a fumed silica admixture had no significant influence on the freeze-thaw durability of the LAC, as opposed to the water demand or porosity structure parameters of the aggregate (Youm et al, 2016). In the case of highstrength LAC, a considerable effect of fumed silica and fly ash on their freeze-thaw durability was observed. The research shows that these admixtures reduce the effect of freeze-thaw cycles on the concrete's E-modulus by about $13 \%$ while reducing weight loss two-three-fold. Moreover, it was found that the fly ash and silica fume content reduces the propagation of microcracks caused by the freezing of water inside the concrete, whereby the stresses generated by freezing and temperature changes are reduced, which can result in higher freeze-thaw durability of concrete containing such admixtures (Gao, Lo, \& Tam, 2002).

Comparative tests of fly ash-based concrete varying in their aggregate modifiers (glass powder and bentonite) have shown that the material from which the aggregate is made has no significant effect on the freeze-thaw durability of the concrete based on this aggregate. The tested LAC did not significantly differ in their freezethaw durability from conventional concrete with a similar composition, but their major mechanical parameters, such as compressive strength and Young's modulus, deteriorated. The compressive strength of the concrete after 28 days was by $29-47 \%$ lower (Kockal \& Ozturan, 2011). Very good freeze-thaw durability results, even better than the ones for conventional concrete, were obtained for LAC when a special admixture in the form of polymer microparticles (contributing to better aggregatecement paste bonding) was used. More than a two-fold lower decrease in weight loss at the same number of freeze-thaw cycles was noted for the LAC in comparison with conventional concrete (Chandra, Aavik, \& Berntsson, 1982). At a higher air entrainment ( $4 \%$ for conventional concrete and $6 \%$ for LAC), tests carried out on the LAC made using artificial lightweight aggregate yielded similar results as the ones for conventional concrete. For the identical amount of entrained air (4\%), the LAC's freeze-thaw resistance was almost 15\% lower than that of conventional concrete (Jo et al, 2007).
Besides the water demand of lightweight aggregate, another parameter important in terms of freeze-thaw durability is the water absorption rate (describing the rate at which water penetrates into aggregate). The higher this rate, the lower the freeze-thaw reliability of the concrete made using the particular LAC. Even though the dependence between the two quantities is nonlinear, the decrease in the freeze-thaw resistance of concrete made using aggregates differing in their water demand can differ as much as fivefold (Buth \& Ledbetter, 1967). The freeze-thaw resistance of LAC is a frequent subject of research papers. Besides the references cited above, this subject is discussed in Polat, Demirboğa, Karakoç and Türkmen (2010); Jóźwiak-Niedźwiedzka (2005); Mao and Ayuta (2008); Pospíchal, Kucharczyková, Misák and Vymazal (2010).

Another interesting group of lightweight concretes are foamed concretes. Unlike LAC, the weight reduction of foamed concrete is not achieved by using lightweight aggregates, but by production of random air-voids in the structure of cementitious matrix. Foamed concrete mechanical and physical properties are highly dependent on the density of the concrete (typically between 280 and $1,800 \mathrm{~kg} / \mathrm{m}^{3}$ ), but research shows that compressive strength up to about $46 \mathrm{MPa}$ can be obtained. Foamed concrete is also characterized by low thermal conductivity of $0.66 \mathrm{~W} / \mathrm{m} \cdot \mathrm{K}$ and can get as low as $0.06 \mathrm{~W} / \mathrm{m} \cdot \mathrm{K}$ (Amran, Farzadnia \& Ali, 2015). These properties make foamed concrete an interesting construction material, which may in some cases prove to be a competition for LAC.

On the basis of the literature survey and the present authors' own research, it is noted here that the way of pre-wetting aggregate is important for the freeze-thaw durability of the LAC. Another aspect that seems to be important is the way of calculating the amount of batched water for a concrete mix. In some lightweight concrete researches and practical applications, the water contained in pre-soaked aggregate or absorbed by dry aggregate is not taken into account in the water-cement ratio. In order to determine the effect of taking or not taking into account the water absorbed by aggregate on the freeze-thaw durability of the LAC, the authors undertook research aimed at demonstrating this dependence.

\section{Aim and scope of experimental tests}

The undertaken tests were to show whether the pre-wetting of lightweight expanded clay aggregate (balls) affects the freeze-thaw durability of the obtained lightweight concrete. Two scenarios were considered: 
A) the water contained in the aggregate (as a result of the pre-wetting of the latter) is taken into account in the water-cement ratio and the amount of water added to the concrete mix is reduced appropriately; and

B) the water contained in the aggregate is not taken into account in the water-cement ratio and the nominal amount of water is added in accordance with the concrete mix design.

The tests covered five series of specimens. Each of the series consisted of $12150 \times 150 \times 150 \mathrm{~mm}$ expanded clay aggregate concrete cubes. All the series were divided into two groups: six cubes were used as the reference specimens and six cubes were subjected to 50 freeze-thaw cycles. The particular number of cycles was adopted considering the 50 years of use and design working life category 4 according to (EN1990, 2002), to which structures (building and other common structures) erected from expanded clay aggregate concrete belong. It should be noted that expanded clay aggregate concrete usually is not exposed (thanks to appropriate insulation) to the capillary rise of water, the action of de-icers, water level fluctuations, etc. Therefore, the assumed freeze-thaw durability corresponding to 50 years of use seems to be absolutely sufficient. The specimens subjected to freeze-thaw cycling were compared with the reference specimens with regard to a possible decrease in strength and weight loss.

\section{Preparation of specimens}

The initial concrete mix design is shown in table 1. This concrete mix design is used to make expanded clay aggregate concrete for the manufacture of large-size precast concrete construction units. The used expanded clay aggregate had the following parameters: fraction size 4-8 mm, particle density $610 \mathrm{~kg} / \mathrm{m}^{3}$ and loose bulk density $325 \mathrm{~kg} / \mathrm{m}^{3}$.

Five series of specimens were prepared. The aggregate was pre-wetted to different degrees. Dry aggregate was used for series 0 , while the nominal pre-wetting degrees of $10 \%$ and $25 \%$ characterized series IA, IB and series IIA, IIB, respectively. Pre-wetting was effected by adding a proper amount of water to containers with expanded clay balls. The water amounted to 10 or $25 \%$ of the aggregate's mass. The containers were tightly closed for $24 \mathrm{~h}$ to prevent moisture and were stored under laboratory conditions in the shade at a temperature of $20^{\circ} \mathrm{C}$. Each of the prepared aggregate series was mixed up every $1 \mathrm{~h}$ during day shift in order to evenly distribute the moisture. After this time, three random expanded clay aggregate samples, each
Table 1: Initial concrete mix design.

\begin{tabular}{ll}
\hline Material & Quantity \\
\hline Portland cement 42.5R & $344 \mathrm{~kg} / \mathrm{m}^{3}$ \\
Water & $178 \mathrm{~kg} / \mathrm{m}^{3}$ \\
Sand 0-2 mm & $821 \mathrm{~kg} / \mathrm{m}^{3}$ \\
Aggregate 2-8 mm (river pebble) & $342 \mathrm{~kg} / \mathrm{m}^{3}$ \\
Expanded clay aggregate 4-8 mm & $274 \mathrm{~kg} / \mathrm{m}^{3}$ \\
Fly ash & $48 \mathrm{~kg} / \mathrm{m}^{3}$ \\
& $(13.9 \%$ cement mass) \\
Superplasticizer FM 6 & $\mathrm{max} .7 .91 \mathrm{~kg} / \mathrm{m}^{3}$ \\
& (max 2.3\% cement mass) \\
W/C & 0.52 \\
\hline
\end{tabular}

Table 2: Aggregate moisture content check results.

\begin{tabular}{llllll}
\hline Series & $\mathbf{0}$ & IA & IIA & IB & IIB \\
\hline Nominal moisture content [\%] & 0 & 10 & 25 & 10 & 25 \\
Actual moisture content [\%] & 0.3 & 11.1 & 24.2 & 8.9 & 24.7 \\
\hline
\end{tabular}

weighing about $500 \mathrm{~g}$, were taken for a moisture content check and compared to prove homogeneity of the batch. The moisture content was measured by weighing before and after drying to a constant mass. The measurement averaged results are presented in table 2. It is apparent that from the technical point of view, the actual degrees of wetting correspond to the nominal values.

Considering the various moisture content of the expanded clay aggregate, only the concrete for series 0 was made in accordance with the initial concrete mix design (tab. 1). For the other test series, the initial concrete mix design was modified. In the case of series IA and IIA, the amount of batched water was reduced so that the w/c ratio took into account the pre-wetting of the aggregate (consequently, the w/c ratio remained the same as in the initial concrete mix design). In the case of series IB and IIB, the pre-wetting of the aggregate was not taken into account, whereby the w/c ratio changed. For series I and II, the mass fraction of expanded clay aggregate was increased by, respectively, $10 \%$ and $25 \%$ on account of the water contained in it. The concrete mix designs used to make series IA, IB, IIA and IIB specimens are compared in table 3.

Twelve $150 \times 150 \times 150 \mathrm{~mm}$ cubes were made within each series. The concrete was compacted using a vibrating table. Specimens belonging to a single series were compacted simultaneously. After $24 \mathrm{~h}$ of storage at the temperature of $20 \pm 2^{\circ} \mathrm{C}$, the formwork was 
Table 3: Concrete mix designs.

\begin{tabular}{lllll}
\hline & IA & IIA & IB & IIB \\
\hline Water added to mix $\left[\mathrm{kg} / \mathrm{m}^{3}\right]$ & 151 & 110 & 178 & 178 \\
Water contained in expanded clay aggregate $\left[\mathrm{kg} / \mathrm{m}^{3}\right]$ & 27 & 68 & 27 & 68 \\
Total water $\left[\mathrm{kg} / \mathrm{m}^{3}\right]$ & 178 & 178 & 205 & 0.60 \\
Actual w/c $[-]$ & 0.52 & 0.52 & 301 & 342 \\
Expanded clay aggregate 4-8 $\left[\mathrm{kg} / \mathrm{m}^{3}\right]$ & 301 & & 342 \\
Other ingredients & acc. to tab. 1 & & 342 \\
\hline
\end{tabular}

removed, and the specimens were placed in a climate chamber. Throughout the whole curing period (27 days), the specimens were stored in the chamber in constant temperature-humidity conditions: at the temperature of $18 \pm 2^{\circ} \mathrm{C}$ and a relative humidity of over $90 \%$. After the curing period (28 days), the specimens were subjected to the testing procedure described in Section 4.

\section{Testing procedure}

All the specimens were measured and weighed. The air-dry bulk density of the expanded clay aggregate was determined. It amounted to $1,657 \mathrm{~kg} / \mathrm{m}^{3}$. Then, the freezethaw cycling test was carried out in accordance with $(P N-B$ 06265, 2018). All the specimens (12 pieces per series) were saturated with water which temperature was $18 \pm 2^{\circ} \mathrm{C}$. Six specimens of each series were left in water throughout the freeze-thaw cycling test. The other six specimens were put into an automatic freezing chamber (fig. 2). They were subjected to freeze-thaw cycles at the temperatures of: -18 $\pm 2^{\circ} \mathrm{C} /+18 \pm 2^{\circ} \mathrm{C}$. The freezing lasted $4 \mathrm{~h}$, and the thawing lasted 2-4 $\mathrm{h}$ and was conducted in water.

After 50 freeze-thaw cycles, the specimens were removed from the chamber, wiped and weighed. The same was done with the reference specimens. Then, all the specimens were subjected to the compression strength test in an Walter+Bai compression press with a capacity of $3,000 \mathrm{kN}$ (fig. 3). The test has been carried out as a loadcontrolled test with a loading rate of $0.5 \mathrm{MPa}$ per second.

\section{Test results}

The mass measurement results for the specimens subjected to freeze-thaw cycling are presented in table 4. The mass before and after cycling is shown for each of the specimens. Moreover, the mean mass values and the

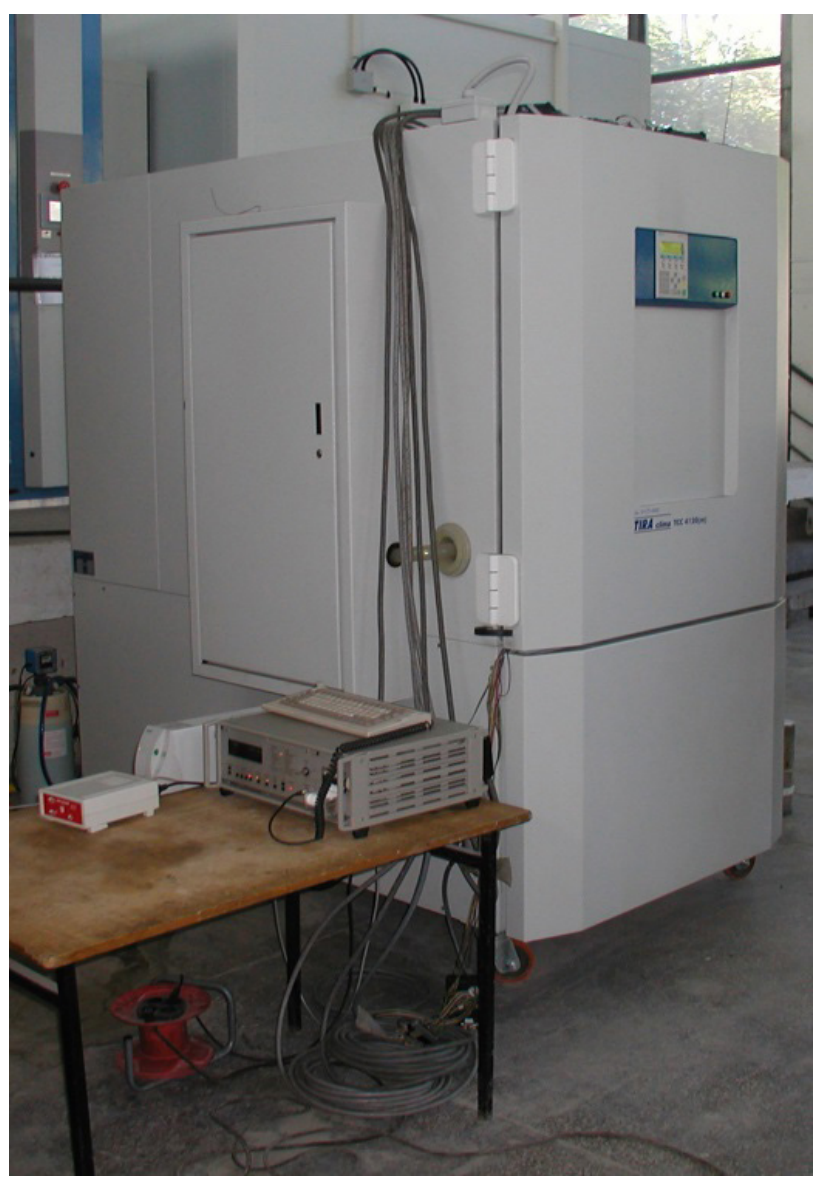

Figure 2: Automatic freezing chamber.

differences between them within each series are given. The mean differences between the masses are also presented in a bar chart (fig. 4).

The compressive strength of the specimens was determined through destructive tests. The test results are presented in table 5. They are also presented graphically in: figure 5 - individual results with means, figure 6 mean values in pairs (the reference specimens and the ones subjected of freeze-thaw cycling). 
Table 4: Masses of specimens.

\begin{tabular}{|c|c|c|c|c|c|c|c|c|c|c|c|}
\hline & & \multicolumn{10}{|c|}{ Masses for particular series [g] } \\
\hline & & 0 & IA & & IIA & & IB & & IIB & & \\
\hline & & $\begin{array}{l}\text { Before } \mathbf{f} / \mathrm{t} \\
\text { cycles }\end{array}$ & $\begin{array}{l}\text { After } \mathrm{f} / \mathrm{t} \\
\text { cycles }\end{array}$ & $\begin{array}{l}\text { Before } \mathrm{f} / \mathrm{t} \\
\text { cycles }\end{array}$ & $\begin{array}{l}\text { After } \mathrm{f} / \mathrm{t} \\
\text { cycles }\end{array}$ & $\begin{array}{l}\text { Before } \mathrm{f} / \mathrm{t} \\
\text { cycles }\end{array}$ & $\begin{array}{l}\text { After } \mathrm{f} / \mathrm{t} \\
\text { cycles }\end{array}$ & $\begin{array}{l}\text { Before } \mathrm{f} / \mathrm{t} \\
\text { cycles }\end{array}$ & $\begin{array}{l}\text { After } \mathrm{f} / \mathrm{t} \\
\text { cycles }\end{array}$ & $\begin{array}{l}\text { Before } \mathrm{f} / \mathrm{t} \\
\text { cycles }\end{array}$ & $\begin{array}{l}\text { After } \mathrm{f} / \mathrm{t} \\
\text { cycles }\end{array}$ \\
\hline \multirow{6}{*}{ 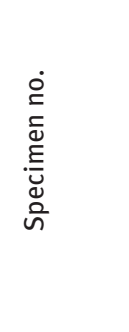 } & 1 & 5622.0 & 5616.6 & 5411.6 & 5405.4 & 5746.2 & 5731.8 & 5574.0 & 5554.4 & 5611.8 & 5596.0 \\
\hline & 2 & 5665.0 & 5660.0 & 5366.0 & 5358.6 & 5807.5 & 5797.6 & 5548.2 & 5531.0 & 5621.0 & 5448.0 \\
\hline & 3 & 5688.8 & 5686.8 & 5409.6 & 5399.2 & 5804.2 & 5784.8 & 5620.2 & 5602.0 & 5715.8 & 5495.1 \\
\hline & 4 & 5673.6 & 5662.8 & 5340.4 & 5332.6 & 5620.0 & 5606.0 & 5532.2 & 5514.2 & 5633.0 & 5501.4 \\
\hline & 5 & 5709.2 & 5707.2 & 5420.4 & 5415.9 & 5508.2 & 5498.8 & 5634.6 & 5617.0 & 5673.0 & 5505.8 \\
\hline & 6 & 5733.6 & 5726.6 & 5389.4 & 5383.8 & 5667.4 & 5657.6 & 5591.4 & 5575.0 & 5848.1 & 5499.0 \\
\hline Mean & & 5682.0 & 5676.7 & 5389.6 & 5382.6 & 5692.3 & 5679.4 & 5583.4 & 5565.6 & 5683.8 & 5507.6 \\
\hline Std Dev & & 38.5 & 39.0 & 31.0 & 31.6 & 117.0 & 115.2 & 40.0 & 40.0 & 89.3 & 48.2 \\
\hline Decrease & & 5.4 & & 7.0 & & 12.8 & & 17.8 & & 176.2 & \\
\hline
\end{tabular}

Relative mass loss $\Delta m_{F}$ (1) and relative decrease in strength $\Delta f_{F}$ (2) caused by freeze-thaw cycling were adopted as the key criteria of expanded clay aggregate concrete freeze-thaw resistance.

$$
\Delta m_{F}=\frac{m_{\mathrm{F} 1}-m_{\mathrm{F} 2}}{m_{\mathrm{F} 1}} \times 100 \%
$$

where: $m_{\mathrm{F} 1}$ - the mean mass of the specimens (six pieces subjected to freeze-thaw cycling) before their first freezing, $m_{\mathrm{F} 2}$ - the mean mass of the specimens (six pieces subjected to freeze-thaw cycling) after their final thawing.

$$
\Delta f_{F}=\frac{f_{\mathrm{F} 1}-f_{\mathrm{F} 2}}{f_{\mathrm{F} 1}} \times 100 \% .
$$

where: $f_{\mathrm{F} 1}$ - the mean compressive strength for the six reference specimens, $f_{\mathrm{F} 2}$ - the mean compressive strength for the six specimens subjected to freeze-thaw cycling after their final thawing.

The parameters calculated from relations (1) and (2) are shown in table 6 and in figures 7 and 8 .

An analysis of the results for series IA and IIA shows that the degree of pre-wetting of the aggregate has an effect on the freeze-thaw durability of the expanded clay aggregate concrete. This effect translates much more into a strength decrease than a mass loss. The trend: the higher the degree of aggregate pre-wetting, the larger the relative decrease in the analysed parameter (mass loss or strength decrease) is observed for both the criteria.

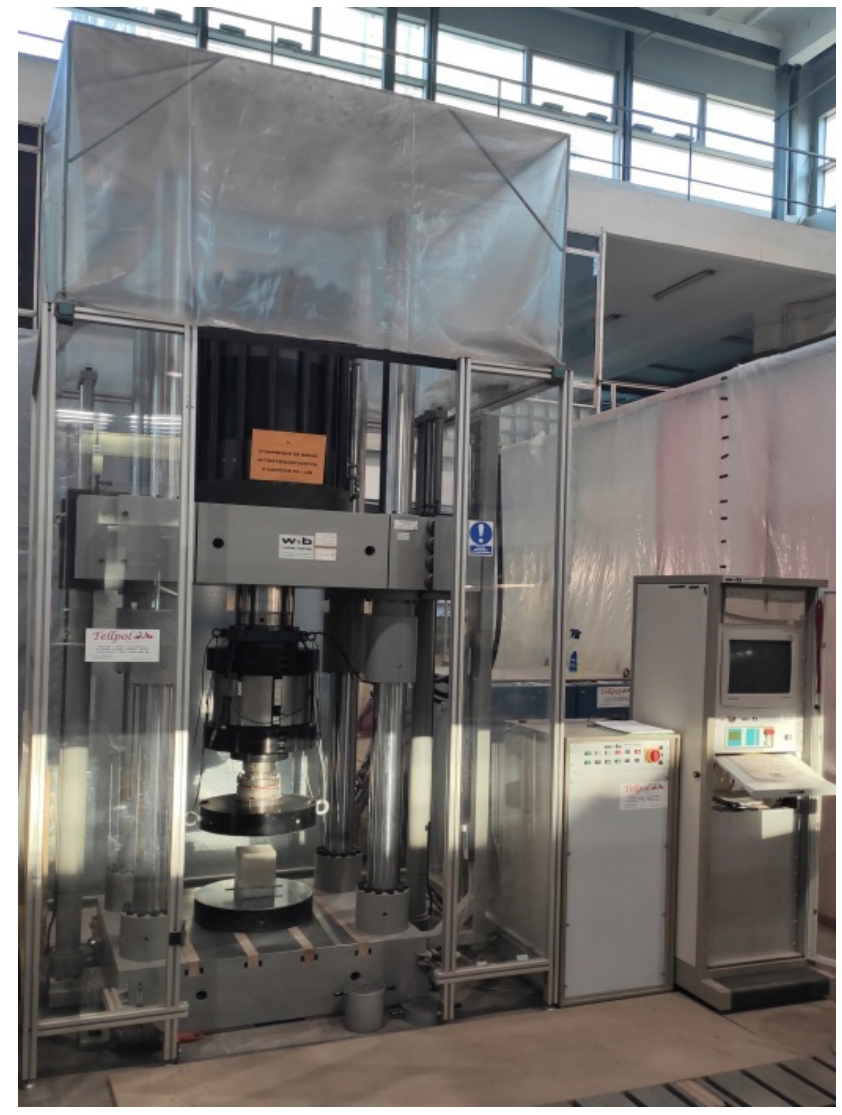

Figure 3: Specimen placed in compression testing machine.

The masses of the specimens showed relative decreases of $0.09,0.13$ and $0.22 \%$ for, respectively, series 0 , IA and IIA (at the pre-wetting degree of 0,10 and 25\%). The 


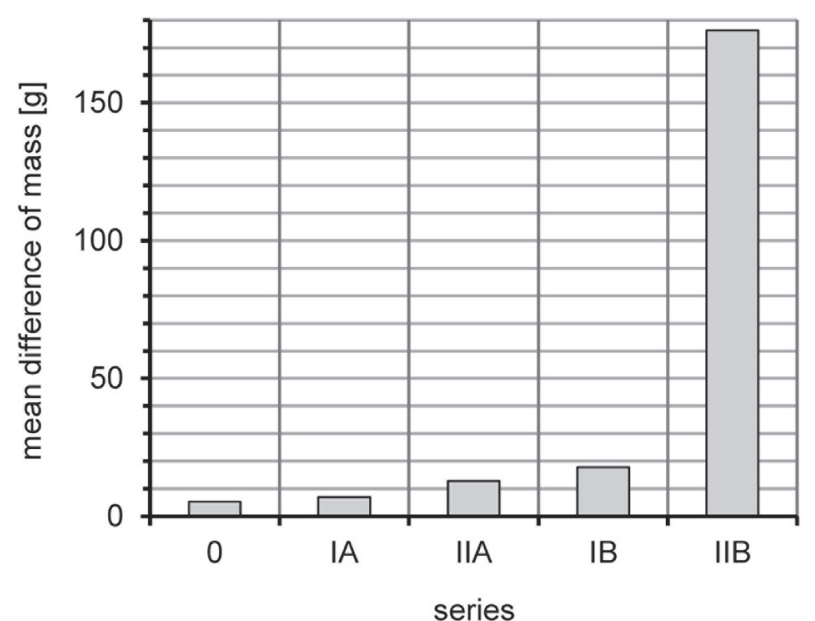

Figure 4: Mean differences between masses of specimens.

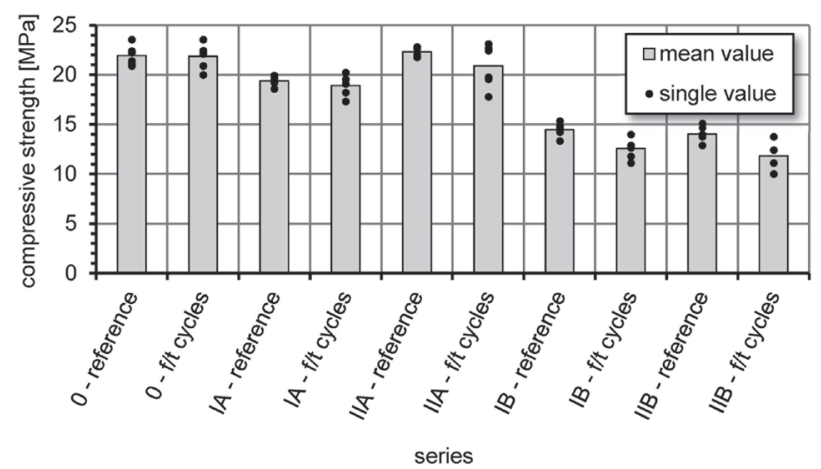

Figure 5: Compressive strength values (individual results and mean values).

Table 5: Compressive strength values.

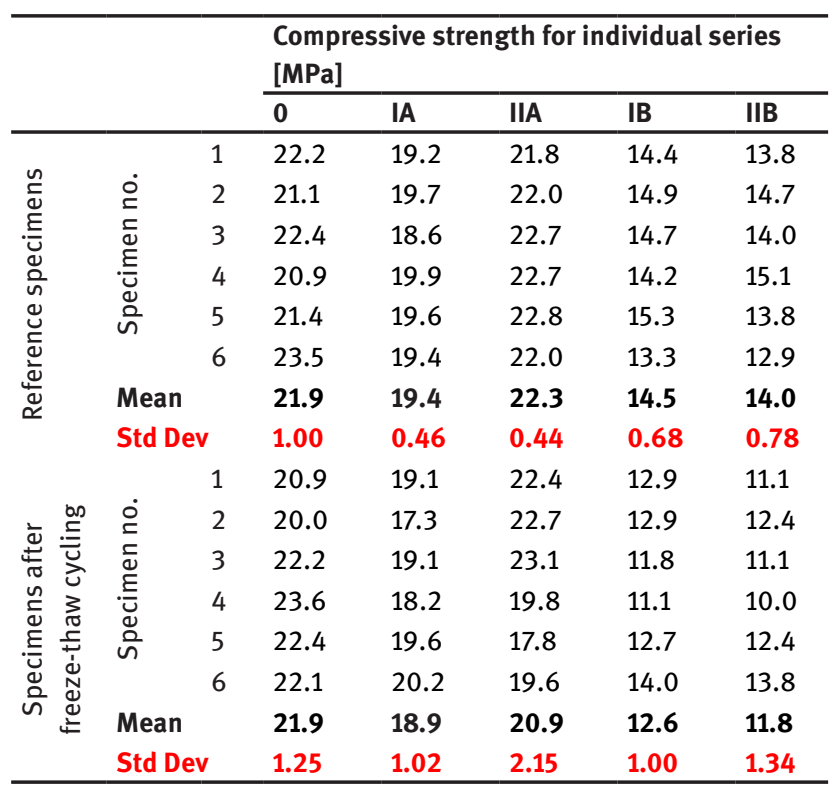

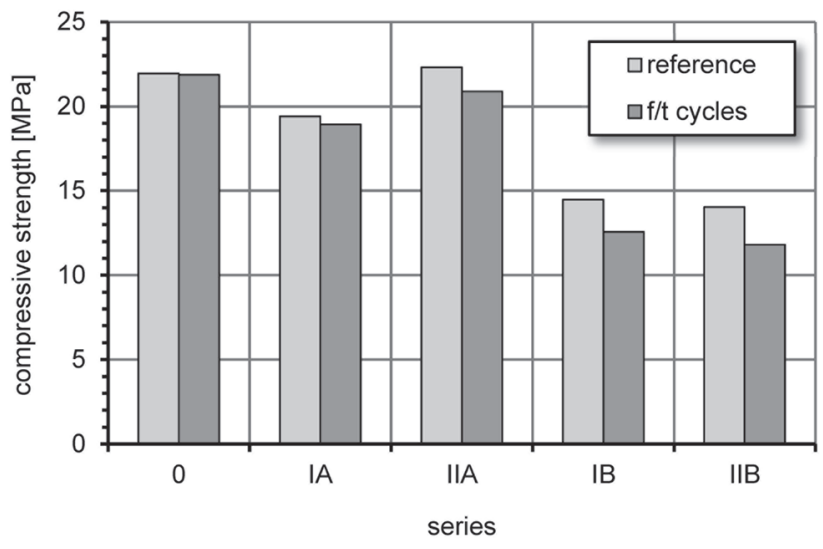

Figure 6: Compressive strength values (mean values).

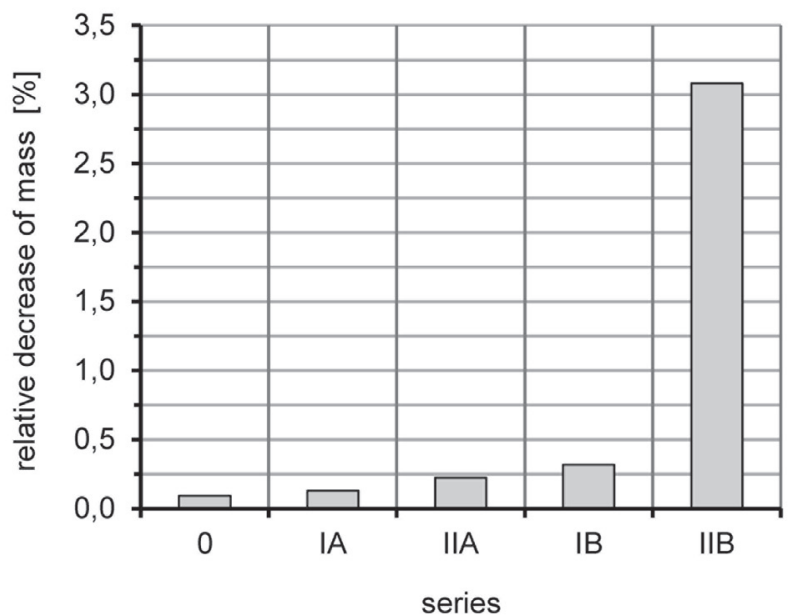

Figure 7: Relative mass losses.

strength decreases were: $0.33,2.50$ and $6.41 \%$. It should be noted that the freeze-thaw test results for series A and B cannot be directly compared. As mentioned in Section 3 , the use of water in an amount that does not take into account the pre-wetting of aggregate results in a change in the w/c ratio. This is clearly reflected already in the 28-day strengths of the expanded clay aggregate concrete (Malaiskiene, Skripkiunas, Vaiciene, \& Karpova, 2017), as illustrated by the graph of compressive strength versus water-cement ratio (fig. 9). If the water contained in the expanded clay aggregate is not taken into account, the obtained concrete has much worse initial mechanical parameters (e.g., compressive strength) and so worse freeze-thaw resistance.

If as in Malaiskiene et al (2017) it is assumed that the boundary values of relative mass loss and relative strength decreases are, respectively, 5 and $20 \%$, all the test series made can be regarded as meeting the requirements of freeze-thaw resistance class F50. However, the aim of the 
Table 6: Relative mass losses $\Delta m_{F}$ and strength decrements $\Delta f_{F^{*}}$

\begin{tabular}{llllll}
\hline & $\mathbf{0}$ & IA & IIA & IB & IIB \\
\hline$\Delta m_{F}[\%]$ & 0.09 & 0.13 & 0.22 & 0.32 & 3.08 \\
$\Delta f_{F}[\%]$ & 0.33 & 2.50 & 6.41 & 13.30 & 15.83 \\
\hline
\end{tabular}

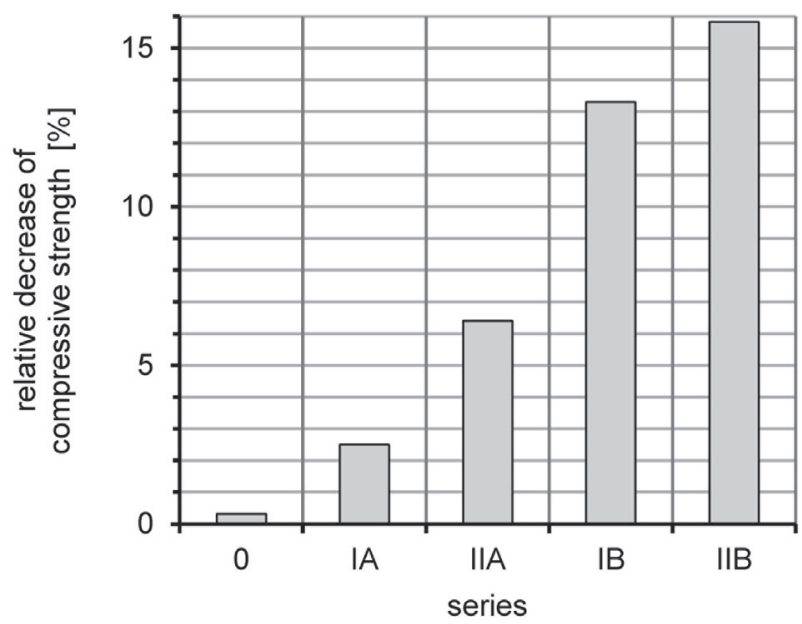

Figure 8: Relative strength decreases.

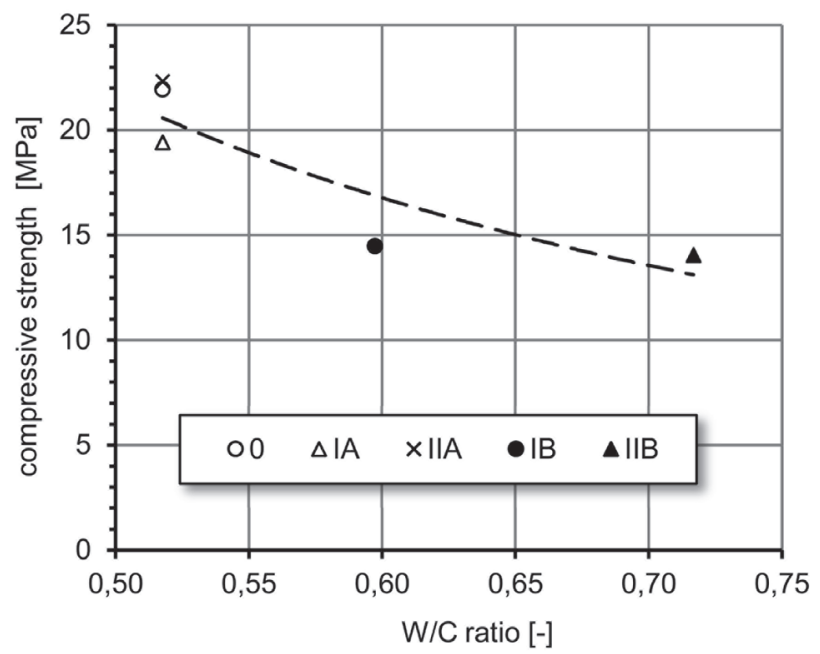

Figure 9: Strength of expanded clay aggregate concrete for reference specimens depending on water-cement ratio.

tests was to verify the general effect of freeze-thaw cycling on freeze-thaw resistance depending on the degree of aggregate pre-wetting. It has been shown that this effect undoubtedly exists. One can suppose that if the number of freeze-thaw cycles had been greater, much larger mass and compressive strength decreases would have been observed.

\section{Conclusions}

The following conclusions can be drawn from the tests carried out as part of this research:

- the pre-wetting of aggregate has an effect on the freeze-thaw durability of the expanded clay aggregate concrete if the amount of water contained in the aggregate is deducted from the amount of mixing water;

- the freeze-thaw cycles to which the specimens were subjected affected much more the specimens' strength decrease than mass loss (as shown in figs. 7 and 8); and

- the pre-wetting of aggregate without taking this fact into account when batching mixing water results in a higher water-cement ratio, whereby the expanded clay aggregate concrete has worse physical and mechanical properties (such as strength and freezethaw resistance).

The research has shown how significant the effect of the storage of expanded clay balls, and the control of their initial moisture content can be in the manufacture of expanded clay aggregate concrete units - the exposure of expanded clay balls to moisture is reflected in the properties of the hardened expanded clay aggregate concrete.

As part of this research, only one expanded clay aggregate concrete mix design was used. In further research, it would be worth to vary the concrete mix design and the initial moisture content of the expanded clay aggregate to determine the effect other parameters, such as the water-cement ratio and the natural aggregate percentage, on the freeze-thaw durability of the concrete.

\section{References}

[1] Amran, Y. H. M., Farzadnia, N., Ali, A. A. A. (2015). Properties and applications of foamed concrete; a review. Construction and Building Materials, 101, 990-1005. https://doi. org/10.1016/j.conbuildmat.2015.10.112

[2] Buth, E.; Ledbetter, W.B. (1967). Research Report 81-3: Aggregate absorption factor as an indicator of the freeze-thaw durability of structural lightweight concrete. Texas: Texas Transportation Institute.

[3] Chandra, S., Aavik, J., \& Berntsson, L. (1982). Influence of polymer microparticles on freeze-thaw resistance of structural lightweight aggregate concrete. International Journal of Cement Composites and Lightweight Concrete, 4(2), 111-115. https:// doi.org/10.1016/0262-5075(82)90015-x 
[4] EN 1990 Eurocode: Basis of structural design. (2002).

[5] Gao, X. F., Lo, Y. T., \& Tam, C. M. (2002). Investigation of microcracks and microstructure of high performance lightweight aggregate concrete. Building and Environment, 37(5), 485-489. https://doi.org/10.1016/s0360-1323(01)00051-8

[6] Haug, A. K., \& Fjeld, S. (1996). A floating concrete platform hull made of lightweight aggregate concrete. Engineering Structures, 18(11), 831-836. https://doi.org/10.1016/01410296(95)00160-3

[7] Jo, B., Park, S., \& Park, J. (2007). Properties of concrete made with alkali-activated fly ash lightweight aggregate (AFLA). Cement and Concrete Composites, 29(2), 128-135. https://doi. org/10.1016/j.cemconcomp.2006.09.004

[8] Jóźwiak-Niedźwiedzka, D. (2005). Scaling resistance of high performance concretes containing a small portion of prewetted lightweight fine aggregate. Cement and Concrete Composites, 27(6), 709-715. https://doi.org/10.1016/j. cemconcomp.2004.11.001

[9] Kockal, N. U., \& Ozturan, T. (2011). Durability of lightweight concretes with lightweight fly ash aggregates. Construction and Building Materials, 25(3), 1430-1438. https://doi. org/10.1016/j.conbuildmat.2010.09.022

[10] Kucharczyková, B., Keršner, Z., Pospíchal, O., Misák, P., \& Vymazal, T. (2010). Influence of freeze-thaw cycles on fracture parameters values of lightweight concrete. Procedia Engineering, 2(1), 959-966. https://doi.org/10.1016/j. proeng.2010.03.104

[11] Kucharczyková, B., Keršner, Z., Pospíchal, O., Misák, P., Daněk, P., \& Schmid, P. (2012). The porous aggregate pre-soaking in relation to the freeze-thaw resistance of lightweight aggregate concrete. Construction and Building Materials, 30, 761-766. https://doi.org/10.1016/j.conbuildmat.2011.12.067

[12] Malaiskiene, J., Skripkiunas, G., Vaiciene, M., \& Karpova, E. (2017). The influence of aggregates type on $W / C$ ratio on the strength and other properties of concrete. IOP Conference Series: Material Science and Engineering, 251, 1-6. https:// iopscience.iop.org/article/10.1088/1757-899X/251/1/012025.

[13] Mao, J., \& Ayuta, K. (2008). Freeze-Thaw Resistance of Lightweight Concrete and Aggregate at Different Freezing Rates. Journal of Materials in Civil Engineering, 20(1), 78-84. https://doi.org/10.1061/(asce)0899-1561(2008)20:1(78)

[14] Neville, A.M. (2011). Properties of concrete ( $5^{\text {th }}$ ed.). Harlow: Pearson Education Ltd.

[15] Ozguven, A., \& Gunduz, L. (2012). Examination of effective parameters for the production of expanded clay aggregate. Cement and Concrete Composites, 34(6), 781-787. https://doi. org/10.1016/j.cemconcomp.2012.02.007

[16] PN-B-06265:2018-10. Concrete. Specification, performance, production and conformity. Domestic supplement of PN-EN 206+A1:2016-12. (in Polish)

[17] Polat, R., Demirboğa, R., Karakoç, M. B., \& Türkmen, İ. (2010). The influence of lightweight aggregate on the physicomechanical properties of concrete exposed to freeze-thaw cycles. Cold Regions Science and Technology, 60(1), 51-56. https://doi.org/10.1016/j.coldregions.2009.08.010

[18] Pospíchal, O., Kucharczyková, B., Misák, P., \& Vymazal, T. (2010). Freeze-thaw resistance of concrete with porous aggregate. Procedia Engineering, 2(1), 521-529. https://doi. org/10.1016/j.proeng.2010.03.056
[19] Rashad, A. M. (2018). Lightweight expanded clay aggregate as a building material - An overview. Construction and Building Materials, 170, 757-775. https://doi.org/10.1016/j. conbuildmat.2018.03.009

[20] Topçu, I. B., \& Işıkdağ, B. (2008). Effect of expanded perlite aggregate on the properties of lightweight concrete. Journal of Materials Processing Technology, 204(1-3), 34-38. https://doi. org/10.1016/j.jmatprotec.2007.10.052

[21] Youm, K.-S., Moon, J., Cho, J.-Y., \& Kim, J. J. (2016). Experimental study on strength and durability of lightweight aggregate concrete containing silica fume. Construction and Building Materials, 114, 517-527. https://doi.org/10.1016/j. conbuildmat.2016.03.165

[21] Amran, Y. H. M., Farzadnia, N., Ali, A. A. A. (2015). Properties and applications of foamed concrete; a review. Construction and Building Materials, 101, 990-1005. https://doi. org/10.1016/j.conbuildmat.2015.10.112 